\title{
The efficacy and safety of intra-articular injection of hyaluronic acid in the knee and physical therapy agents to treat Kashin-Beck disease: A prospective interventional study
}

\author{
PINGLIN YANG ${ }^{1}$, XIONG GUO $^{2}$, XIJING HE $^{1}$, QUANJIN ZANG ${ }^{1}$, GUOYU WANG $^{1}$, \\ PENG $\mathrm{XU}^{3}$ and WEIZHUO WANG ${ }^{1}$ \\ ${ }^{1}$ Department of Orthopedics Surgery, The Second Affiliated Hospital, College of Medicine, \\ Xi'an Jiaotong University, Xi'an, Shaanxi 710004; ${ }^{2}$ Department of Public Health, Medical College, \\ Key Laboratory of Environment and Genes Related to Diseases, Xi'an Jiaotong University, \\ Ministry of Education; ${ }^{3}$ Xi'an Red Cross Hospital, Xi'an, Shaanxi 710061, P.R. China
}

Received December 17, 2015; Accepted May 13, 2016

DOI: $10.3892 /$ etm.2016.3364

\begin{abstract}
The aim of the present study was to determine whether hyaluronic acid (HA) or physical therapy agents (PTA) can improve functional parameters in patients with knee Kashin-Beck disease (KBD). For 2 years, patients $(n=55)$ were treated with HA weekly for 5 weeks, then received 6th and 7th injections on the 3rd and 6th month, respectively, for 7 injections in total. Patients $(n=53)$ were treated with PTA five times a week for 3 weeks every month for 6 months. The patients were evaluated with the Western Ontario and McMaster University Osteoarthritis Index (WOMAC) and the visual analog pain scale (VAS). Trial registration, ChiCTR-TRC-12002189 (http://www.chictr. org/). During the study, following treatment interruption, pain increased in the PTA group (from a mean value of $85.7 \pm 83.8 \mathrm{~mm}$ at month 12 to $145.2 \pm 128.8 \mathrm{~mm}$ at month 18 and $201.3 \pm 150.5 \mathrm{~mm}$ at month 24$)$, while it remained stable in the HA group (from a mean value of $80.7 \pm 70.6 \mathrm{~mm}$ at month 12 to $90.1 \pm 95.2 \mathrm{~mm}$ at month 18 and $82.6 \pm 85.3 \mathrm{~mm}$ at month 24), with a statistically significant difference in favor of HA at month $18(\mathrm{P}<0.05)$ and month $24(\mathrm{P}<0.05)$. Joint stiffness, physical function and total WOMAC showed the same trend as pain. The global efficacy judgments by the patients and the investigators showed a statistically significant difference in favor of HA at month $18(\mathrm{P}<0.05)$ and month $24(\mathrm{P}<0.05)$. In conclusion, although all the patients improved in terms of pain and function, HA was superior to PTA alone for pain relief and lasting effect.
\end{abstract}

Correspondence to: Dr Weizhuo Wang, Department of Orthopedics Surgery, The Second Affiliated Hospital, College of Medicine, Xi'an Jiaotong University, 157 West Fifth Road, Xi'an, Shaanxi 710004, P.R. China

E-mail:pyg586@163.com

Key words: hyaluronic acid, Kashin-Beck disease

\section{Introduction}

Kashin-Beck disease (KBD) is an endemic osteochondropathy, mainly located in Eastern Siberia in Russia, the diagonal broad belt extending from the Northeast to the Southwest of China, affecting over 0.642 million patients with 37,917 million people at risk $(1,2)$. Clinically, the disease manifests as deformed, enlarged interphalangeal joints with shortened fingers, and limited range of motion (ROM) in the joints of the extremities, which develops in 4 stages (3). Similar to other degenerative joint diseases, the large weight-bearing joints are the most degenerated in adult KBD patients, especially the knee joint. The primary aim of the therapeutic management of $\mathrm{KBD}$, referring to osteoarthritis $(\mathrm{OA})$, is pain relief, protection of ROM, and prevention of secondary functional disability and joint damage. No medical intervention has been shown to arrest disease progression or reverse joint damage and few studies can be found on the validity of medical therapy methods at present (4-6). It is therefore important to identify a useful therapeutic regimen for KBD.

Intra-articular injections, such as those with sodium hyaluronic acid (HA), are widely used in the treatment of knee OA. Although HA has been shown to affect chondrocytes, synoviocytes, and the inflammatory process, it has been demonstrated that the primary objective of HA injections is visco-supplementation of the joint, which aims to increase the elastic viscous properties and restoration of the rheological properties of the synovial fluid in the arthritic joints (7). For the treatment with HA, most studies reported that clinical improvement begins with a delayed onset between 2 and 5 weeks, lasting 6 months or up to 1 year (7-9). Literature reviews revealed that few studies observed the effects of HA on KBD, even though the benefits of HA therapy on OA patients are well known (10-12).

Physical therapy agents (PTA) play an important role in the treatment of OA of the knee. Deep heat such as short waves and electrotherapeutic modalities such as interferential therapy are used to treat acute and chronic pain associated with OA (13-19). 
Our use of HA started based on empirical evidence, in an attempt to improve mobility and reduce pain in KBD patients, with knee deformity. After witnessing an initial result within the first year, we performed a formal clinical trial, which was undertaken between August 2006 and March 2009. The aim was to study the effects of HA therapy on the clinical signs and evolution of the disease.

\section{Patients and methods}

Patients. The present study was performed with the approval of the Xi'an Jiaotong University Ethics Committee and in compliance with the Helsinki Declaration (register no. ChiCTR-TRC-12002189 http://www.chictr.org/).

The study was a clinical trial: two intervention treatments including intra-articular HA injections in the knee and PTA were conducted within 48 months of follow-up. We examined patients with KBD of the knee joint according to the national diagnosis criteria of KBD in China $(3,20)$. All 123 patients had grade II knee KBD, radiologically confirmed according to the analysis of X-ray films of the right hand, knee and hip joints. The patients suffered pain in the affected knee that continued for at least 6 months. Patients were excluded from the study if they had received intra-articular injections in the joint and/or attended physiotherapy sessions for the affected knee, within the 6 months prior to the study, if they had a history of allergy or hypersensitivity to drugs or eggs, or if they were ascertained or suspected to be pregnant or were lactating. Patients were also excluded if they had a known or suspected joint infection or a specific condition (neoplasm, diabetes mellitus, paresis, osteonecrosis, or recent trauma) or poor general health status that would interfere with the functional assessments during the study. Baseline characteristics (weight, height, age, gender and related radiological assessment of the knee and radiological degree) were recorded prior to the treatment. Laboratory assessment (according to standard methods) made at the entry and after 6 months included the following evaluation: routine hematological variables, and functional tests of the kidney and liver.

Treatments. The patients were divided into the HA or PTA group ( $\mathrm{n}=62$ and 61 per group, respectively). Each participant was informed with regard to the study and provided signed consent for treatment. In patients with bilateral disease, the more painful knee was treated. Patients in the first group received HA. The test drug was $20 \mathrm{mg}$ sodium hyaluronate $(20 \mathrm{mg} / 2 \mathrm{ml}$, 500-700,000; Shanghai Qisheng Biological Preparation Co., Ltd, Shanghai, China), $(\rightarrow 3)-2$-acetamido-2-deoxy- $\beta$ D-glucopyranosyl- $(1 \rightarrow 4)-\beta$-D-glucopyranosyluronic acid- $(1 \rightarrow)$ $\mathrm{n}, \mathrm{C}_{14} \mathrm{H}_{20} \mathrm{NNaO}_{11}$. Injections were performed by two physicians in an anterolateral approach (along the patellar tendon) with the knee in $90^{\circ}$ flexion, and an evaluator unaware of each patient's treatment group, not present at the time or place of each weekly injection, assessed the patients for their symptoms and side effects at baseline and at first injection, 1 week later. A volume of $2 \mathrm{ml}$ was injected intra-articularly into each knee joint once a week for five consecutive weeks without local anesthetics. Strict sterile procedures were applied to prevent septic infection. The 6th injection was carried out in the 3rd month and the 7 th injection was carried out in the 6th month.
PTA were applied to each patient of the other group, five times a week for 3 weeks every month for 6 months with a series of infrared (IRH-3100; Korea), short-wave diathermy pulsed patterns and interferential therapy. Each of them was continued for approximately $20 \mathrm{sec}$, for $1 \mathrm{~h}$.

Clinical assessments were made at the start of the study, and at 1,3,6,12, 18 and 24 months.

The patients could use paracetamol (to a maximum of $2 \mathrm{~g}$ daily) during the study period as considered appropriate by the physician. The use of NSAIDs was not permitted during the study period; any pretreatment with NSAIDs had to be discontinued 15 days before the start of the study. Patients were withdrawn from the study if a severe reaction to the injections occurred or if there was evidence of an active infection in the injected joint at any time during the study period.

Efficacy parameters. The primary efficacy criterion was joint pain measured using WOMAC A visual analog pain scale (VAS). Secondary efficacy variables included joint stiffness (WOMAC B) and physical function (WOMAC C), total WOMAC, Short Form 36 (SF-36) health survey questionnaire, daily paracetamol consumption, global efficacy judgment by the patient and the investigator using a four-point scale ('How well do you feel the treatment has worked thus far?', i.e., not effective, slightly effective, moderately effective, very effective), presence of effusion or swelling of soft tissue, and tenderness of the signal joint (VAS) assessed by palpation along the joint line.

Safety parameters. Vital signs were recorded at baseline and at every visit. Blood and urine samples were collected at screening, at week 1 and at the end of treatment (week 4) for laboratory safety analyses. Adverse events (AEs) were recorded at each visit and assessed by the investigator. Patients were asked to assess the tolerability of the study treatment globally ('How well did you tolerate the treatment?') at each visit after baseline using a 5-point rating scale (nil, poor, moderate, good, very good). The investigators also provided a judgment on tolerability ('How well do you think the patient tolerated the treatment?') using the same scale. In both groups the following clinical parameters were used to assess the response to the treatment: the ROM of both knees (measurement with a goniometer of active extension and flexion. However, only flexion was measured because none of the patients had restriction of extension), time to walk a distance of $15 \mathrm{~m}$ (measured with a stop-watch and reported in sec), amount of soft tissue swelling and synovial effusion (measured by a meter on volar patellar area and noted if patellar click sign was present by bimanual examination).

Statistical analysis. SPSS for Windows software was used for data management and statistical analysis. Primary analyses were conducted by intent-to-treat using the last observation carried forward technique for missing data, with participants analyzed according to their initial assignment. To compare the groups with regard to demographic measurements, the independent samples t-test or Chi-square test were used between the group analyses. The differences between groups were verified by independent samples t-test. The repeated measurement variables in each group (HA or PTA) were analyzed using analysis of variance (ANOVA) (general linear model for 


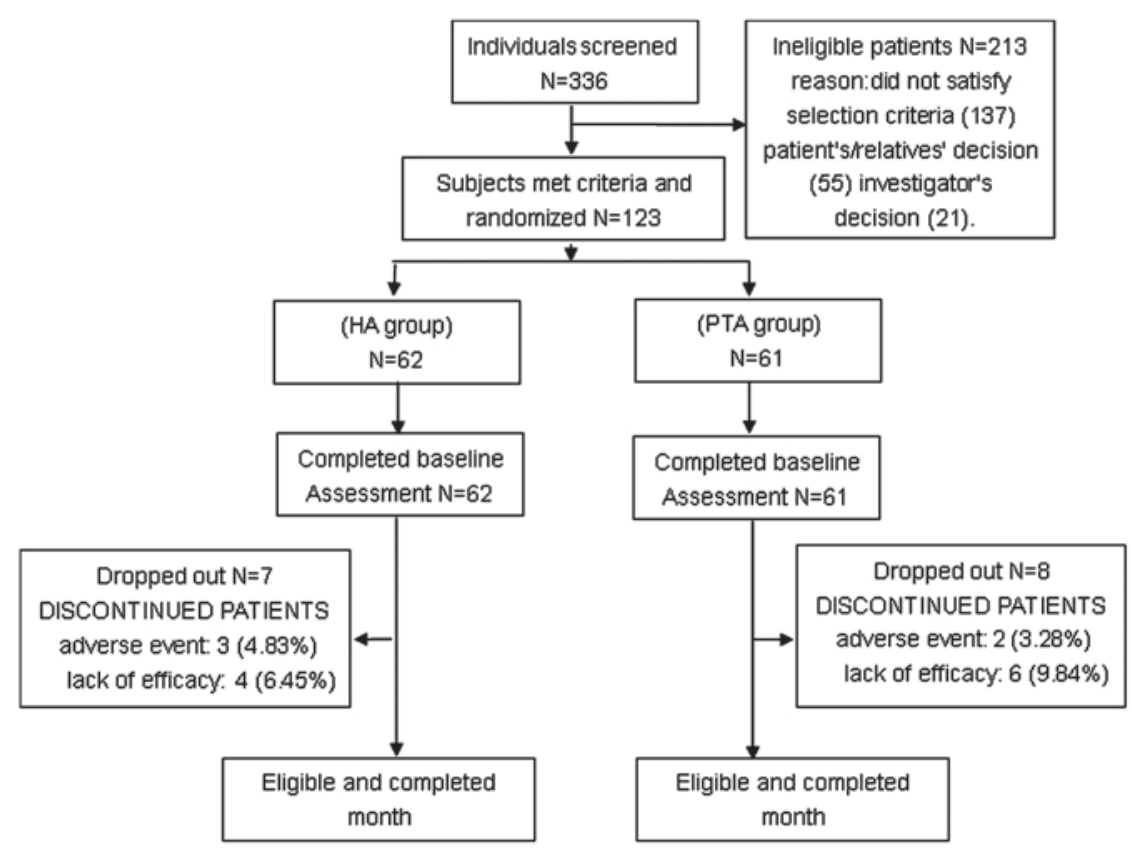

Figure 1. Patient disposition.

repeated measures). The level of significance was set at 0.05 for all statistical tests. All tests of hypotheses and reported P-values were two-sided.

\section{Results}

From a pool of 336 individuals, 123 met the screening criteria (Fig. 1). Of the 123 patients, 62 patients were randomized into the HA group and the remaining 61 patients in the PTA group. All participants were given a baseline assessment. Fifteen patients ( 7 patients in the HA group and 8 patients in the PTA group) dropped out of the study between month 1 and month 24 of assessments due to an adverse event, lack of effectiveness, loss to follow-up or patient decision. A total of 108 patients completed the 24-month study (Fig. 1). The remaining 108 patients (55 in the HA group and 53 in the PTA group) were considered eligible for an effectiveness analysis.

Baseline characteristics. Table I shows baseline demographic data, KBD symptoms, and prior treatment for all the patients eligible for an effectiveness analysis. The two randomized groups were comparable at baseline, and there were no significant differences between the groups for these parameters $(\mathrm{P}<0.05)$. In addition, there were no relevant differences in baseline values for the other efficacy parameters (Table I; Fig. 2).

Efficacy results. The mean values and the Student's t-test statistics for the efficacy parameters are shown in Table II. The primary efficacy parameter, pain on WOMAC A, decreased to a similar extent in the two groups during the 12-month treatment period: from a mean value of $285.1 \pm 70.0 \mathrm{~mm}$ VAS at baseline to $85.7 \pm 83.8 \mathrm{~mm}$ at 12 months in the PTA group and from $278.0 \pm 65.0 \mathrm{~mm}$ at baseline to $80.7 \pm 70.6 \mathrm{~mm}$ at 12 months in the HA group. Although HA appeared to have a faster onset of efficacy at month 1 , there were no statistically
Table I. Demographic and clinical characteristics of patients at baseline.

\begin{tabular}{lccc}
\hline Characteristics & HA group & PTA group & P-value \\
\hline $\mathrm{N}$ & 55 & 53 & \\
Age (years) & $62.4 \pm 9.0$ & $58.7 \pm 8.3$ & $\mathrm{NS}$ \\
Female $/ \mathrm{male}(\%)$ & $40 / 15(72.7 / 27.3)$ & $35 / 18(64.2 / 34.0)$ & $\mathrm{NS}$ \\
$\mathrm{BMI}\left(\mathrm{kg} / \mathrm{m}^{2}\right)$ & $30.1 \pm 5.2$ & $30.9 \pm 2.3$ & $\mathrm{NS}$ \\
Stiffness (min) & $9.6 \pm 8.2$ & $10.5 \pm 6.1$ & $\mathrm{NS}$ \\
Right/left (\%) & $36 / 19(65.5 / 34.5)$ & $35 / 18(66.0 / 34.0)$ & $\mathrm{NS}$ \\
Range of & $118.6 \pm 12.3$ & $121.3 \pm 9.0$ & $\mathrm{NS}$ \\
motion (degree) & & & \\
Peripheral & $42.6 \pm 4.1$ & $41.2 \pm 2.6$ & $\mathrm{NS}$ \\
measurement of & & & \\
knee (m) & & & \\
\end{tabular}

HA group, patients who received intra-articular hyaluronic acid injections; PTA group, patients treated with physical therapy agents. Values are the mean \pm SD. NS, not significant; HA, hyaluronic acid; PTA, physical therapy agents.

significant differences between the groups during the treatment period showing that PTA is as effective as HA for pain reduction.

However, following treatment interruption, pain increased rapidly in the PTA group (from a mean value of $85.7 \pm 83.8 \mathrm{~mm}$ at month 12 to $145.2 \pm 128.8 \mathrm{~mm}$ at month 18 and $201.3 \pm 150.5 \mathrm{~mm}$ at month 24) while it remained stable in the HA group (from a mean value of $80.7 \pm 70.6 \mathrm{~mm}$ at month 12 to $90.1 \pm 95.2 \mathrm{~mm}$ at month 18 and $82.6 \pm 85.3 \mathrm{~mm}$ at month 24$)$ with a statistically significant difference in favor of HA at month $18(\mathrm{P}<0.05)$ and month $24(\mathrm{P}<0.05)$ (Table II).

Joint stiffness (WOMACB), physical function (WOMAC C) and total WOMAC showed the same trend as WOMAC A 
Table II. Efficacy parameters-mean absolute values and MW statistics.

\begin{tabular}{|c|c|c|}
\hline WOMAC $($ mean \pm SD) & HA $(n=55)$ & PTA $(n=53)$ \\
\hline \multicolumn{3}{|l|}{ WOMAC A } \\
\hline Baseline & $278.0 \pm 65.0$ & $285.1 \pm 70.0$ \\
\hline Month 1 & $166.2 \pm 84.3^{\mathrm{a}}$ & $190.5 \pm 93.6$ \\
\hline Month 3 & $123.2 \pm 85.9^{\mathrm{a}}$ & $136.1 \pm 94.8^{\mathrm{a}}$ \\
\hline Month 6 & $90.3 \pm 74.2^{\mathrm{a}}$ & $102.0 \pm 92.7^{\mathrm{a}}$ \\
\hline Month 12 & $80.7 \pm 70.6^{\mathrm{a}}$ & $85.7 \pm 83.8^{\mathrm{a}}$ \\
\hline Month 18 & $90.1 \pm 95.2^{\mathrm{a}}$ & $145.2 \pm 128.8$ \\
\hline Month 24 & $82.6 \pm 85.3^{\mathrm{a}}$ & $201.3 \pm 150.5$ \\
\hline \multicolumn{3}{|l|}{ WOMAC B } \\
\hline Baseline & $124.8 \pm 38.5$ & $125.5 \pm 45.6$ \\
\hline Month 1 & $75.2 \pm 37.9^{\mathrm{a}}$ & $89.7 \pm 48.5^{\mathrm{a}}$ \\
\hline Month 3 & $55.3 \pm 38.8^{\mathrm{a}}$ & $65.2 \pm 45.0^{\mathrm{a}}$ \\
\hline Month 6 & $39.6 \pm 33.3^{\mathrm{a}}$ & $45.7 \pm 42.1^{\mathrm{a}}$ \\
\hline Month 12 & $32.6 \pm 34.0^{\mathrm{a}}$ & $38.9 \pm 36.7^{\mathrm{a}}$ \\
\hline Month 18 & $36.3 \pm 36.5^{\mathrm{a}}$ & $64.6 \pm 48.9^{\mathrm{a}}$ \\
\hline Month 24 & $36.1 \pm 37.2^{\mathrm{a}}$ & $56.9 \pm 56.2^{\mathrm{a}}$ \\
\hline \multicolumn{3}{|l|}{ WOMAC C } \\
\hline Baseline & $875.1 \pm 265.3$ & $901.8 \pm 252.5$ \\
\hline Month 1 & $556.6 \pm 313.1$ & $643.9 \pm 354.1$ \\
\hline Month 3 & $453.2 \pm 312.5^{\mathrm{a}}$ & $518.4 \pm 311.3^{\mathrm{a}}$ \\
\hline Month 6 & $326.0 \pm 266.0^{\mathrm{a}}$ & $357.5 \pm 310.2^{\mathrm{a}}$ \\
\hline Month 12 & $245.4 \pm 260.2^{\mathrm{a}}$ & $305.0 \pm 279.1^{\mathrm{a}}$ \\
\hline Month 18 & $313.7 \pm 317.6^{\mathrm{a}}$ & $448.5 \pm 403.5^{\mathrm{a}}$ \\
\hline Month 24 & $297.8 \pm 322.9^{\mathrm{a}}$ & $639.0 \pm 516.5$ \\
\hline \multicolumn{3}{|l|}{ WOMAC total } \\
\hline Baseline & $1253.2 \pm 354.3$ & $1293.6 \pm 343.8$ \\
\hline Month 1 & $768.0 \pm 406.6^{\mathrm{a}}$ & $928.4 \pm 481.7$ \\
\hline Month 3 & $603.7 \pm 416.7^{\mathrm{a}}$ & $712.6 \pm 482.1$ \\
\hline Month 6 & $451.9 \pm 366.4^{\mathrm{a}}$ & $512.1 \pm 451.2^{\mathrm{a}}$ \\
\hline Month 12 & $357.7 \pm 346.1^{\mathrm{a}}$ & $415.1 \pm 424.0^{\mathrm{a}}$ \\
\hline Month 18 & $441.2 \pm 450.4^{\mathrm{a}}$ & $658.3 \pm 586.4$ \\
\hline Month 24 & $421.8 \pm 454.0^{\mathrm{a}}$ & $896.6 \pm 652.3$ \\
\hline \multicolumn{3}{|l|}{ SF-36 (sum score) } \\
\hline Baseline & $358.0 \pm 114.2$ & $355.3 \pm 121.6$ \\
\hline Month 18 & $556.6 \pm 142.3^{\mathrm{a}}$ & $507.9 \pm 136.7^{\mathrm{a}}$ \\
\hline Month 24 & $542.9 \pm 156.6^{\mathrm{a}}$ & $514.1 \pm 146.7^{\mathrm{a}}$ \\
\hline
\end{tabular}

HA group, patients who received intra-articular hyaluronic acid injections. PTA group, patients treated with physical therapy agents. ${ }^{a} \mathrm{P}<0.05$ compared with baseline, calculated on the median percent change. Values are the mean \pm SD. HA, hyaluronic acid; PTA, physical therapy agents; WOMAC, Western Ontario and McMaster University Osteoarthritis Index.

(Table II; Fig. 2). Tenderness on palpation decreased in the two groups with a significant difference $(\mathrm{P}<0.05)$ (Table II).

The global efficacy judgments by the patients and the investigators are presented in Table III and confirm the slow onset of efficacy of HA with $76.4 \%$ in this group compared with $56.6 \%$ of the patients in the PTA group judging that their treatment was 'moderately effective' to 'very effective' at month 1 . The judgments were comparable in the two treatment groups at the end of the treatment. At month 12, a significantly $(\mathrm{P}<0.001)$ greater proportion of HA-treated patients $(78.1 \%)$ assessed treatment as 'moderately effective' to 'very effective', compared to $41.5 \%$ of those treated with PTA while at month 24 , these figures were $65.4 \%$ in the HA group and $30.2 \%$ in the PTA group $(\mathrm{P}<0.001)$.

Safety. Three patients of the HA group withdrew from the study due to adverse reactions (malaise, tachycardia and hypotension). The events occurred after the first injection. Two cases of adverse event were observed in the PTA patients. No clinically significant changes occurred in the laboratory parameters or other vital signs in either group.

\section{Discussion}

HA is a non-sulfated, non-epimerized, linear glycosaminoglycan (GAG) existing in vivo as a polyanion of HA and composed of repeating disaccharide units of D-glucuronic acid and N-acetyl-D-glucosamine (->4GlcAbeta1$>3$ GlcNAcbeta1->) $(7,8)$. It is a constituent of the extracellular matrix (ECM) of the skin, joints, eye, and many other tissues and organs. In the joint, HA is an important component of the extracellular matrix of the cartilage (21). It is present in the superficial layers of the synovial membrane and is found at high concentration in the synovial fluid (22-28). HA plays a key role in preserving the structural and functional integrity of the cartilage matrix and in regulating a variety of cellular activities through specific cellular receptors and molecular interactions in addition to maintaining the viscoelastic properties of synovial fluid. In vitro and in vivo studies have shown that HA can induce proteoglycan synthesis and aggregation, stimulate synoviocytes to produce more HA, modulate the inflammatory response, reduce chemotaxis and leucocyte migration and exert scavenger activity on free oxygen radicals (5). These activities are mediated by the binding of HA with intercellular adhesion molecule-1 (ICAM-1), CD44 integrin and the receptor for HA-mediated motility (RHAMM), all of which are expressed on the surface of various cell types, including inflammatory cells, synoviocytes and chondrocytes. HA injected in the joint has a half-life of approximately $20 \mathrm{~h}$ when joints are normal and approximately $12 \mathrm{~h}$ when joints are inflamed (29). The above evidence shows that the clinical effects of HA are due to its pharmacological action on the cellular and tissue components of the joint. Therefore, it can be excluded that the sustained beneficial effects of HA on symptoms and clinical signs of KBD, such as OA, can be accounted only for a temporary restoration of the synovial fluid viscoelasticity.

The effect of HA on KBD may be related to inhibiting the levels of cytokines, specific cellular receptors, and molecular interactions. It was reported that sodium HA administration has a dose-dependent effect in vitro to promote the proliferation and inhibition of apoptosis of chondrocytes from patients with KBD $(30,31)$. Phenotypic expression of types I, II, III, and X collagen and MMP-13 in chondrocytes cultured in vitro were significantly different between the KBD and control cultures, showing degenerative and hypertrophic changes in chondrocytes of KBD articular cartilage (30). Increases of the levels of tumor necrosis factor (TNF)- $\alpha$, vascular endothelial 

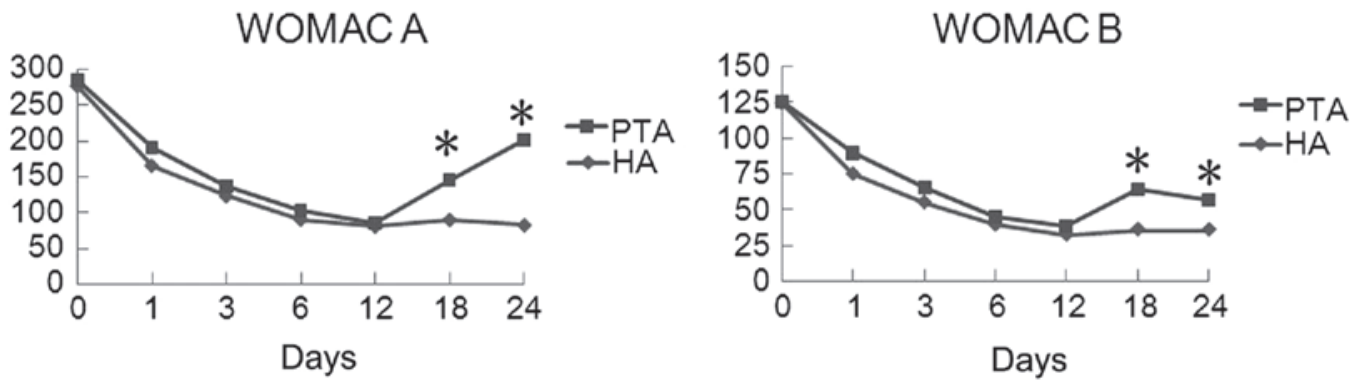

WOMAC C
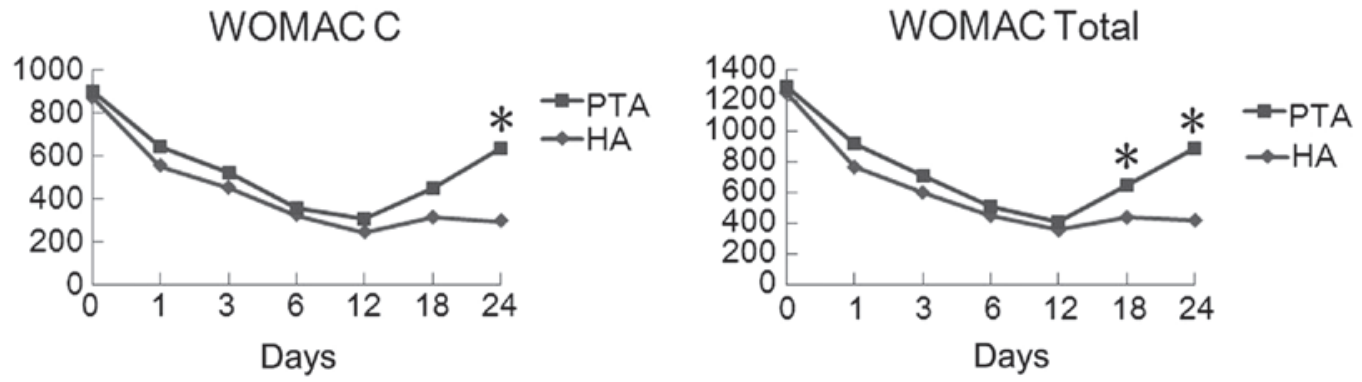

Figure 2. Mean WOMAC subscale levels decreased in all patients followed by an increase for PTA and HA groups. *This decrease was significant between PTA and HA group $(\mathrm{P}<0.05)$. HA group, patients who received intra-articular hyaluronic acid injections; PTA group, patients treated with physical therapy agents Values are the mean \pm SD. WOMAC, Western Ontario and McMaster University Osteoarthritis Index; PTA, physical therapy agents; HA, hyaluronic acid.

Table III. Clinical assessments of the drug treatments (global efficacy judgments by the patients and the investigator).

\begin{tabular}{|c|c|c|c|c|c|c|}
\hline \multirow[b]{2}{*}{ Effective (\%) } & \multicolumn{2}{|c|}{ HA $(n=55)$} & \multicolumn{2}{|c|}{ PTA $(n=53)$} & \multicolumn{2}{|c|}{ P-value } \\
\hline & $\mathrm{a}$ & $\mathrm{b}$ & $\mathrm{a}$ & $\mathrm{b}$ & $\mathrm{a}$ & $\mathrm{b}$ \\
\hline Month 1 & & & & & 0.042 & 0.144 \\
\hline Not & 9.1 & 11.0 & 20.8 & 17.0 & & \\
\hline Slightly & 14.5 & 12.7 & 22.6 & 24.5 & & \\
\hline Moderately & 36.4 & 40.0 & 28.3 & 28.3 & & \\
\hline Very & 40.0 & 36.4 & 28.3 & 30.2 & & \\
\hline Month 6 & & & & & 0.003 & 0.013 \\
\hline Not & 7.3 & 9.1 & 13.2 & 11.3 & & \\
\hline Slightly & 10.9 & 12.7 & 35.8 & 35.8 & & \\
\hline Moderately & 5.5 & 40.0 & 30.2 & 32.1 & & \\
\hline Very & 36.4 & 36.4 & 20.8 & 20.8 & & \\
\hline Month 12 & & & & & 0.001 & 0.002 \\
\hline Not & 12.7 & 9.1 & 28.3 & 4.5 & & \\
\hline Slightly & 9.1 & 12.7 & 30.2 & 30.2 & & \\
\hline Moderately & 43.6 & 38.2 & 24.5 & 22.6 & & \\
\hline Very & 34.5 & 8.2 & 17.0 & 22.6 & & \\
\hline Month 24 & & & & & 0.001 & 0.001 \\
\hline Not & 20.0 & 21.8 & 39.6 & 43.4 & & \\
\hline Slightly & 14.5 & 12.7 & 30.2 & 26.4 & & \\
\hline Moderately & 23.6 & 21.8 & 13.2 & 13.2 & & \\
\hline Very & 41.8 & 43.6 & 17.0 & 17.0 & & \\
\hline
\end{tabular}

a, efficacy judgment by the patient. b, efficacy judgment by the investigator. HA group, patients who received intra-articular hyaluronic acid injections. PTA group, patients treated with physical therapy agents. Values are the mean \pm SD. HA, hyaluronic acid; PTA, physical therapy agents.

growth factor (VEGF) and interleukin (IL)-1 $\beta$ may play a role in the pathogenesis of KBD. Terminal chondrocytes differentiation, PTHrP, transforming growth factor (TGF)- $\beta 1$, and
VEGF expression was altered showing degenerative changes in KBD cartilage (32-36). Previous findings showed that HA can promote the proliferation of chondrocytes and has 
effects on the differentiation of these cells (24-26,37). In vitro experiments showed that HA can enhance the synthesis of extracellular matrix proteins, including chondroitin and keratin sulfate, while suppressing cartilage damage by fibronectin fragments in vitro and in vivo (24,37-40).

The present findings have shown that while an improvement was observed in the functions of all patients, pain intensity decreased more rapidly and to lower levels with the use of HA. In the present study, pain relief by the WOMAC pain subscale was observed in the first month in the two groups. Similarly, this pattern of decrease in pain was also observed by VAS.

Whether HA was used or not, the improvement in function was persistent during the first year. The use of HA injections should be considered for rapid and prolonged effect in the improvement of knee KBD. Our findings support that HA injections could lead to better results in pain reduction.

Our study has several limitations which must be considered. The number of patients studied was small due to medical costs, increasing the power of the study to show significant effects. Second, since there was no other medicine-treated group, such as a saline solution group, perhaps the HA treatment may not be more effective than intra-articular or other drugs. However, the main objective of this study was to assess the effects of HA on the management of knee KBD, not to compare the effects of different drug therapies. Furthermore, HA has been demonstrated to be effective, and has been found to be superior to placebo injections, and comparative studies have shown the differences between timing of onset of effects, as reported above. In conclusion, this study demonstrates that HA provides rapid pain relief, has beneficial effects during the first year following treatment, and is well tolerated in the management of knee KBD. For the treatment of patients with knee $\mathrm{KBD}$, our findings support that HA should be the preferred therapeutic option.

In conclusion, the results of this study support the observation that PTA is a useful, safe and well-tolerated treatment for patients with knee OA, and who are receiving hyaluronan therapy. Although all patients showed improvement for pain and function, HA therapy was superior to PTA alone for pain relief and had a longer lasting effect.

\section{Acknowledgements}

This study was supported by the Ministry of Science and Technology (no. 2006DFA33610), the Natural Scientific Fund of China (no. 30630058,81001225), the International Co-operative Fund in Shaanxi, China and Finland (no. 2005KW-13), China and University of Buffalo, USA (no. 08143004), and the Fundamental Research Funds for the Central Universities (no. 08140003).

\section{References}

1. Chinese Health Statistical Digest: http://www.moh.gov.cn/ publicfiles/business/htmlfiles/mohwsbwstjxxzx/s9092/201206/ 55044.htm.2012

2. Yamamuro T: Kashin-Beck disease: a historical overview. Int Orthop 25: 134-137, 2001.

3. Xiong G: Diagnostic, clinical and radiological characteristics of Kashin-Beck disease in Shaanxi Province, PR China. Int Orthop 25: 147-150, 2001.
4. Yue J, Yang M, Yi S, Dong B, Li W, Yang Z, Lu J, Zhang R and Yong J: Chondroitin sulfate and/or glucosamine hydrochloride for Kashin-Beck disease: a cluster-randomized, placebo-controlled study. Osteoarthritis Cartilage 20: 622-629, 2012.

5. Tang X, Pei FX, Zhou ZK, Liu G, Shen B, Kang PD, Li J, Zhao XD, Li Q and Li Y: A randomized, single-blind comparison of the efficacy and tolerability of hyaluronate acid and meloxicam in adult patients with Kashin-Beck disease of the knee. Clin Rheumatol 31: 1079-1086, 2012.

6. Mathieu F, Suetens C, Begaux F, De Maertelaer V and Hinsenkamp M: Effects of physical therapy on patients with Kashin-Beck disease in Tibet. Int Orthop 25: 191-193, 2001.

7. Shimizu M, Higuchi H, Takagishi K, Shinozaki T and Kobayashi T: Clinical and biochemical characteristics after intra-articular injection for the treatment of osteoarthritis of the knee: prospective randomized study of sodium hyaluronate and corticosteroid. J Orthop Sci 15: 51-56, 2010.

8. Briem K, Axe MJ and Snyder-Mackler L: Functional and perceived response to intra-articular hyaluronan injection in patients with knee osteoarthritis: persistence of treatment effects over 5 months. Knee Surg Sports Traumatol Arthrosc 17: 763-769, 2009.

9. Bannuru RR, Natov NS, Obadan IE, Price LL, Schmid CH and McAlindon TE: Therapeutic trajectory of hyaluronic acid versus corticosteroids in the treatment of knee osteoarthritis: a systematic review and meta-analysis. Arthritis Rheum 61: 1704-1711, 2009.

10. Liang KY: Research progress of intraarticular injection of hyaluronic acid (HA) for osteoarthritis in recent three years. Zhongguo Gu Shang 23: 962-964, 2010 (In Chinese).

11. Yasuda T: Progress of research in osteoarthritis. Pharmacological effects of hyaluronic acid. Clin Calcium 19: 1644-1652, 2009 (In Japanese).

12. Akasaki Y, Matsuda S and Iwamoto Y: Progress of research in osteoarthritis. The anti-inflammatory effects of intra-articular injected statin on experimental osteoarthritis. Clin Calcium 19: 1653-1662, 2009 (In Japanese).

13. Lin $\mathrm{H}$ and $\mathrm{He} \mathrm{C}$ : Progress of foreign clinical research of exercise therapy of knee osteoarthritis. Zhongguo Xiu Fu Chong Jian Wai Ke Za Zhi 22: 1389-1392, 2008 (In Chinese).

14. Brakke R, Singh J and Sullivan W: Physical therapy in persons with osteoarthritis. PM R 4 (Suppl): S53-S58, 2012.

15. Gonçalves RS, Cabri J and Pinheiro JP: Evaluation of patient characteristics as predictors of health status in knee osteoarthritis patients referred for physical therapy. Acta Reumatol Port 36: 137-144, 2011.

16. Pisters MF, Veenhof C, Schellevis FG, De Bakker DH and Dekker J: Long-term effectiveness of exercise therapy in patients with osteoarthritis of the hip or knee: a randomized controlled trial comparing two different physical therapy interventions. Osteoarthritis Cartilage 18: 1019-1026, 2010.

17. Benito Peinado PJ, Cupeiro Coto R and Calderón Montero FJ: Physical exercise as non pharmacologic therapy in knee osteoarthritis. Reumatol Clin 6: 153-160, 2010 (In Spanish).

18. Kladny B: Physical therapy of osteoarthritis. Z Rheumatol 64: 448-455, 2005 (In German).

19. Mayer ME: Physical therapy and exercise in osteoarthritis of the knee. Ann Intern Med 132: 923, 2000.

20. Farooq U, Xiong G, Irshad R and Yaqoob S: Pattern of joints involvement in Kashin-Beck disease: a local osteochondropathy in China. J Ayub Med Coll Abbottabad 22: 97-100, 2010.

21. Olczyk P, Komosinska-Vassev K, Winsz-Szczotka K, Kuznik-Trocha K, and Olczyk K: Hyaluronan: structure, metabolism, functions, and role in wound healing. Postepy Hig Med Dosw (Online) 62: 651-659, 2008 (In Polish).

22. Schiavinato A, Finesso M, Cortivo R and Abatangelo G: Comparison of the effects of intra-articularinjections of Hyaluronan and its chemically cross-linked derivative (Hylan G-F20) in normal rabbit knee joints. Clin Exp Rheumatol 20: 445-454, 2002.

23. Kitano T, Ateshian GA, Mow VC, Kadoya Y and Yamano Y: Constituents and $\mathrm{pH}$ changes in protein rich hyaluronan solution affect the biotribological properties of artificial articular joints. J Biomech 34: 1031-1037, 2001.

24. Nehrer S, Chiari C, Domayer S, Barkay H and Yayon A: Results of chondrocyte implantation with a fibrin-hyaluronan matrix: a preliminary study. Clin Orthop Relat Res 466: 1849-1855, 2008.

25. Echigo R, Mochizuki M, Nishimura R and Sasaki N: Suppressive effect of hyaluronan on chondrocyte apoptosis in experimentally induced acute osteoarthritis in dogs. J Vet Med Sci 68: 899-902, 2006. 
26. Knudson CB, Nofal GA, Pamintuan L and Aguiar DJ: The chondrocyte pericellular matrix: a model for hyaluronan-mediated cell-matrix interactions. Biochem Soc Trans 27: 142-147, 1999.

27. Cortivo R, Brun P, Cardarelli L, O'Regan M, Radice M, and Abatangelo G: Antioxidant effects of hyaluronan and its alpha-methyl-prednisolone derivative in chondrocyte and cartilage cultures. Semin Arthritis Rheum 26: 492-501, 1996.

28. Knudson W and Knudson CB: Assembly of a chondrocyte-like pericellular matrix on non-chondrogenic cells. Role of the cell surface hyaluronan receptors in the assembly of a pericellular matrix. J Cell Sci 99: 227-35, 1991.

29. Magdalou J, Netter P, Fournel-Gigleux S and Ouzzine M: Agrecan and articular cartilage: assessment of glycosyltransferases for the restoration of cartilage matrix in osteoarthritis J Soc Biol 202: 281-288, 2008 (In French).

30. Gao Z, Guo X, Duan C, Ma W, Xu P, Liu R, Gu Q and Chen J: In vitro effects of sodium hyaluronate on the proliferation and the apoptosis in chondrocytes from patients with Kashin-Beck disease and osteoarthritis. J Nanjing Med Univ 23: 104-110, 2009.

31. Tanaka M, Masuko-Hongo K, Kato T, Nishioka $\mathrm{K}$ and Nakamura H: Suppressive effects of hyaluronan on MMP-1 and RANTES production from chondrocytes. Rheumatol Int 26 : $185-190,2006$

32. Tang X, Zhou Z, Shen B, Yang J, Kang P, Li J, Crook N, Li Q, Min L and Pei F: Serum levels of TNF- $\alpha$, IL-1 $\beta$, COMP, and CTX-II in patients with Kashin-Beck disease in Sichuan, China Rheumatol Int 32: 3503-3509, 2012

33. Yan D, Kang P, Shen B, Yang J, Zhou Z, Duan L and Pei F: Serum levels of IL-1 $\beta$, IL- 6 and TNF- $\alpha$ in rats fed with Kashin-Beck disease-affected diet. Int J Rheum Dis 13: 406-411, 2010.
34. Guo X, Zuo H, Cao CX, Zhang Y, Geng D, Zhang ZT, Zhang YG, von der Mark K and von der Mark H: Abnormal expression of Col X, PTHrP, TGF-beta, bFGF, and VEGF in cartilage with Kashin-Beck disease. J Bone Miner Metab 24: 319-328, 2006.

35. Wang SJ, Guo X, Ren FL, Zhang YG, Zhang ZT, Zhang FJ and Geng D: Comparison of apoptosis of articular chondrocytes in the pathogenesis of Kashin-beck disease and primary osteoarthritis. Zhongguo Yi Xue Ke Xue Yuan Xue Bao 28: 267-270, 2006 (In Chinese)

36. Wang SJ, Guo X, Zuo H, Zhang YG, Xu P, Ping ZG, Zhang Z and Geng D: Chondrocyte apoptosis and expression of Bcl-2, Bax, Fas, and iNOS in articular cartilage in patients with Kashin-Beck disease. J Rheumatol 33: 615-619, 2006.

37. Grad S, Lee CR, Gorna K, Gogolewski S, Wimmer MA and Alini M: Surface motion upregulates superficial zone protein and hyaluronan production in chondrocyte-seeded three-dimensional scaffolds. Tissue Eng 11: 249-256, 2005.

38. Lin LC, Chang SJ, Lin CY, Lin YT, Chuang CW, Yao CH, and Kuo SM: Repair of chondral defects with allogenous chondrocyte-seeded hyaluronan/collagen II microspheres in a rabbit model. Artif Organs 36: E102-109, 2012.

39. Eshed I, Trattnig S, Sharon M, Arbel R, Nierenberg G, Konen E and Yayon A: Assessment of cartilage repair after chondrocyte transplantation with a fibrin-hyaluronan matrix - correlation of morphological MRI, biochemical T2 mapping and clinical outcome. Eur J Radiol 81: 1216-1223, 2012.

40. Barbucci R, Torricelli P, Fini M, Pasqui D, Favia P, Sardella E, d'Agostino R and Giardino R: Proliferative and re-defferentiative effects of photo-immobilized micro-patterned hyaluronan surfaces on chondrocyte cells. Biomaterials 26: 7596-7605, 2005. 